\title{
Phytochemical Investigation and Antioxidant Activity of Root Extract of Aloe gilbertii Reynolds, from Konso, Southern Ethiopia
}

\author{
Nebiyu Chali Yadeta \\ Department of Chemistry, Arba Minch University, Arba Minch, Ethiopia
}

Email address:

chali.nebiyu@yahoo.com,nebiyu.chali@amu.edu.et

\section{To cite this article:}

Nebiyu Chali Yadeta. Phytochemical Investigation and Antioxidant Activity of Root Extract of Aloe gilbertii Reynolds, from Konso, Southern Ethiopia. American Journal of Applied Chemistry. Vol. 7, No. 5, 2019, pp. 130-136. doi: 10.11648/j.ajac.20190705.11

Received: September 16, 2019; Accepted: October 14, 2019; Published: October 23, 2019

\begin{abstract}
Aloe gilbertii belonging to the family Aloaceae is used by local people for treatment various disease such as malaria and wound healing. The main purpose of this study was to investigate phytochemicals and antioxidant activity of the Root Extract of Aloe gilbertii Reynolds Phytochemical screening of the $\mathrm{CH}_{2} \mathrm{Cl}_{2}: \mathrm{CH}_{3} \mathrm{OH}(1: 1)$ extract revealed the presence of flavonoids, anthraquinone, Alkaloids, saponins, phenol and absence of steroids and phytosterols. The anti-oxidant potential and total antioxidant potential was determined by using reducing power determination method and phosphomolybdate method respectively. The antioxidant capacity of methanol, ethanol and ethyl acetate root extracts fractions of Aloe gilbertii were found to be $244.5 \pm 0.631,241.5 \pm 0.112$ and $106 \pm 1.05 \mathrm{mg}$ of ascorbic acid per $10 \mathrm{mg}$ of dry weight of antioxidant in the reducing power, respectively and it's total antioxidant capacity of these extract fractions were $82.21 \pm 0.028,88.75 \pm 0.016$ and $74.85 \pm 0.043 \mathrm{mg}$ of ascorbic acid per $10 \mathrm{mg}$ of dry weight of the crude extract. Thus, the results of the present investigation infer that this plant extracts possess potent antioxidant. Therefore it is strongly recommended to isolate the antioxidant components
\end{abstract}

Keywords: Aloaceae, Aloe gilbertii, Antioxidant Potential, FRAP Assay, Total Antioxidant Capacity

\section{Introduction}

The rapid rise of degenerative diseases worldwide is threatening economic and social development as well as the lives and health of millions of people. It represents a major health challenge to global development in the coming century. It is estimated that up to $80 \%$ of cardiovascular disease, $90 \%$ of Type II diabetes, and one third of cancers can be avoided by changing lifestyle, including diet [1]. Dietrelated high cholesterol, high blood pressure, obesity, and insufficient consumption of fruits and vegetables have been cited as significant interlinking risk factors that cause the majority of these diseases [2].

It is now widely believed that at the epicenter of these diseases are highly reactive chemical species known as free radicals - electrically charged or neutral species having at least one unpaired electron. Cell damage caused by free radical-induced chain reaction appears to be a major contributor to aging and degenerative diseases such as cataracts, immune system decline, brain dysfunction, and many more [3].

In recent years there is an ever-increasing curiosity in studying the role of free radicals in biological system, because of their pivotal role in various physiological conditions as well as their involvement in a diverse range of diseases. The free radicals, both the reactive oxygen species (ROS) and reactive nitrogen species (RNS), are derived from both endogenous sources and exogenous sources [4].

The ROS/RNS play a twofold job as both beneficial and toxic compounds to the living system. At moderate or low levels ROS/RNS have beneficial effects and involve in various physiological functions such as in immune function (i.e. defense against pathogenic microorganisms), in a number of cellular signaling pathways, in mitogenic response and in redox regulation [5]. But at higher concentration, both ROS as well as RNS generate oxidative stress and nitrosative stress, respectively, causing potential damage to the biomolecules. The oxidative stress and nitrosative stress are 
developed when there is an excess production of ROS/RNS on one side and a deficiency of enzymatic and non-enzymatic antioxidants on the other side [6].

If free radicals overwhelm the body's ability to regulate them, a condition known as oxidative stress ensues. A balance between free radicals and antioxidants is necessary for proper physiological function. Hence application of external source of antioxidants can assist in coping this oxidative stress. Synthetic antioxidants such as butylated hydroxytoluene and butylated hydroxyanisole have recently been reported to be dangerous for human health. Thus, the search for effective, nontoxic natural compounds with antioxidative activity has been intensified in recent years [7].

The buildup of ROS in the body is counteracted by various beneficial compounds known as antioxidants. Antioxidants are capable of stabilizing, or deactivating, free radicals thereby safeguarding cells from oxidative damage. The health-beneficiary effect of antioxidants is ascribed to their ability to break up the free radical-induced chain reactions during the propagation process by providing a hydrogen atom or an electron to the free radical and receiving the excess energy possessed by the activated molecule [8].

Plants have not only nutritional value but also, in the eyes of the local people, they have medicinal and ritual or magical values [9]. The ethno medicinal healing systems vary across cultures. In Ethiopia, there is cultural diversity with various patterns of using the flora [10].

According to the World Health Organization (WHO), more than 3.5 billion people in the developing world rely on medicinal plants as components of their healthcare [11]. The vast majority of people $(70-80 \%)$ in Africa consult Traditional Medical Practitioners (TMPs) for their healthcare [12]. Traditional medicine has been brought into focus for meeting the goals of a wider coverage of primary healthcare delivery, not only in Africa but also, in all countries of the world. It is the first choice healthcare treatment for at least $80 \%$ of Africans who suffer from high fever and other common ailments [13]. Thus; medicinal plants are widely used in the treatment of numerous human and livestock diseases in different parts of the world.

Crude drug from medicinal plants embraces through consideration of primary and secondary metabolites derived as a result of plant metabolism. The compounds that are responsible for medicinal properties of the drug are usually secondary metabolites such as flavanoid, alkaloids, saponnins, tannins, terpenoides and their derivatives.

Antioxidant activity of phenolic compounds is associated with the annular structure of the molecule, conjugated double bonds and the presence of functional groups in the ring. The antioxidant activity of phenolic is possible through various mechanisms of action: inhibition of the ROS formation and the ROS trapping and the extinction of singlet oxygen; and reducing the chelated metal ions (which are the catalysts for reactions leading to the formation of ROS), interrupting the cascade of free radical reactions in lipid peroxidation and protecting the other compounds with antioxidant activity [14-17].
The Genus of Aloe:-The genus Aloe L. comprises approximately 420 species with centers of diversity in southern and east Africa, the Arabian Peninsula and Madagascar [18]. The genus is an important source of biologically active compounds with well over 130 phytochemical constituents isolated from the group [19]. Out of which 46 are endemic to Ethiopia. It effective in treating stomach ailments, gastrointestinal problems, skin diseases, constipation for radiation injury, for its anti-inflammatory effect, for wound healing and burns, as an antiulcer and diabetes. Currently the plant is widely used in skin care, cosmetics and as nutraceuticals.

The different parts of Aloe gilbertii are used for the treatment of various diseases in traditional or folk remedies throughout the world. Leaves and root parts have been used by local people mainly for treatment of malaria and wounds [20]. Aloe gilbertii Reynolds is one of the most valuable medicinal plant which provide a realistic alternative form of treatment for a variety of local ailments including malaria, leishmanaiasis, hypertension, stomach pain, asthma, epilepsy, diarrhea, diabetes, wound healing, leprosy etc. However, to the best of our knowledge, there is no significant research were done on the phytochemical investigation and antioxidant activity of the root extract of this plant. The investigation of chemical constituent and antioxidant activity may contribute to a better understanding on the chemical content of Aloe gilbertii. Moreover, it is also used as a reference for other researchers those are interested on the phytochemical investigation and antioxidant activity of aloe gilbertii reynolds.

Therefore, the main objective of this research is to investigate phytochemicals and antioxidant potential of Aloe gilbertii using a variety of standard phytochemical test and antioxidant evaluation parameters.

\section{Materials and Methods}

\subsection{Chemicals}

Methanol, Glacialacid, Distilledwater, potassiumferricyanide, Acetone, Ethanol, Hexane, Ferrcchloride, Hydrochloricacid, Leadacetate, Trichloroaceticacid, con. sulfericacid, Ascorbicacid, Sodiumdihydrogenphosphate (INDIA),

Disodiumhydrogenphosphate (INDIA), potassiumferriccyanide, potassium iodide, sodium hydroxide, sodium phosphate, ammonium molybdate.

\subsection{Materials}

Conical flask, what man filter paper, $\mathrm{PH}$ meter, volumetric flask, water bath,

Uv-visible Spectrophotometry Vu-65, measuring cylinder, electrical beam balance, Beaker, rotatory vapor, centrifuge Test tube, thermometer.

\subsection{Preparation of Reagents}

Preparation of $0.2 \mathrm{M}$ sodium phosphate: Phosphate buffer was prepared according to Buffer-maker software database as follows. First $0.5 \mathrm{M}$ solution of each of sodium dihydrogen phosphate (sodium phosphate monobasic) and disodium 
hydrogen phosphate (sodium phosphate dibasic) were prepared separately by transferring $7.8 \mathrm{gm}$ of sodium dihydrogen phosphate dehydrate $\left(\mathrm{NaH}_{2} \mathrm{PO}_{4} \cdot 2 \mathrm{H}_{2} \mathrm{O}\right)$ and 7.10 gm of disodium hydrogen phosphate $\left(\mathrm{Na}_{2} \mathrm{HPO}_{4}\right)$ into $100 \mathrm{~mL}$ flask. Following dissolution, water was added up to the mark. A $0.2 \mathrm{M}$ phosphate buffer of $\mathrm{pH}=6.6$, was prepared by mixing $50.45 \mathrm{~mL}$ of sodium dihydrogen phosphate and 49.55 $\mathrm{mL}$ of disodium hydrogen phosphate solutions in $250 \mathrm{~mL}$ flask. Finally the $\mathrm{pH}$ of the buffer solution was adjusted by a $\mathrm{pH}$ meter using $1 \mathrm{M}$ of $\mathrm{HCl}$ and $2 \mathrm{M}$ of $\mathrm{NaOH}$ solution.

Preparation of phsophomolybdate: Phosphomolybdate reagent was prepared by mixing $0.6 \mathrm{M}$ sulfuric acid $(100 \mathrm{~mL}), 4$ $\mathrm{mM}$ ammonium molybdate $(100 \mathrm{~mL})$ and $28 \mathrm{mM}$ sodium phosphate $(100 \mathrm{~mL})$ solution into $300 \mathrm{~mL}$ volumetric flask.

\subsection{Standard Solution Preparation}

Ascorbic acid solution (0.1\%): $0.1 \mathrm{~g}$ of ascorbic acid was dissolved in $100 \mathrm{~mL}$ of distilled water in volumetric flask having the concentration of $1000 \mathrm{ppm}$. From the solution, 5, $25,50,100$ and $200 \mathrm{ppm}$ of series of solution were prepared following conventional procedure; dilution law. The solutions thus prepared were used for ascorbic acid calibration curve to determine the antioxidant power of the root extracts in reducing power method. From the stock solution of ascorbic acid standard above, 25, 50,100, 200 and $400 \mathrm{ppm}$ were prepared for the determination of total antioxidant capacity of the root extract of Aloe gilbertii Reynolds in phosphomolbdate assay.

\subsection{Reducing Power Determination Method: FRAP Assay}

The reducing power of each fraction was determined according to a literature procedure [26] Variable concentrations of the different fractions $2.5 \mathrm{~mL}(0.2-$ $1 \mathrm{mg} / \mathrm{mL})$ were mixed with sodium phosphate buffer $(2.5 \mathrm{~mL}$, $0.2 \mathrm{M}, \mathrm{pH} 6.6)$ and potassium ferricyanide $(2.5 \mathrm{~mL}, 1.0 \%)$. The mixtures were incubated at $50^{\circ} \mathrm{C}$ for $20 \mathrm{~min}$. Then $10 \%$ trichloroacetic acid $(2.5 \mathrm{~mL})$ was added and centrifuged at $300 \mathrm{rpm}$ for $10 \mathrm{~min}$. The upper layer of the solution $(5.0 \mathrm{~mL})$ was decanted and diluted with $5.0 \mathrm{~mL}$ of water. Ferric chloride $(0.1 \mathrm{~mL}, 0.1 \%)$ was added and absorbance was read at $700 \mathrm{~nm}$. Ascorbic acid was used as a standard in the range of $(0.05-0.2 \mathrm{mg} / \mathrm{mL}) .0 .6 \mathrm{mg} / \mathrm{mL}$ of the crude extract and its fractions were taken to determine the antioxidant power of the extract in terms of ascorbic acid standard.

\subsection{Total Antioxidant Capacity Determination Method: Phosphomolybdate Assay}

The antioxidant activity of samples was evaluated by the green phosphomolybdenum complex formation according to the method of reported elsewhere. The principle of this method is based on the reduction of phosphomolybdic acid to phosphomolybdenum blue complex by sodium sulfide. The obtained phosphomolybdenum blue complex is oxidized by the addition of nitrite and this causes a reduction in intensity of the blue color.

In a test tube, $3 \mathrm{~mL}$ of phosphomolybdate reagent, $600 \mu \mathrm{L}$
$(0.6 \mathrm{~mL})$ of the plant extract, standard solution and water as a blank were taken and mixed. The test tubes were capped with foil and incubated in water bath at $95^{\circ} \mathrm{C}$ for $90 \mathrm{~min}$. After the contents of the test tubes were cooled down, the absorbance of the test tube contents were measured at $695 \mathrm{~nm}$ against a blank. Ascorbic acid was used as a standard. The total antioxidant activities of the extracts were expressed as milligram per milliliter of ascorbic acid equivalents $(\mathrm{mg} / \mathrm{mL}$ of AAE) per dry weight of the sample at $1 \mathrm{mg} / \mathrm{mL}$ of the crude extract and its fractions.

\subsection{Sample Collection and Preparation}

The roots of Aloe gilbertii Reynolds were collected in June 2016 from Konso Wereda, in Gamo gofa Zone of SNNPR Ethiopia, Ethiopia, about $80 \mathrm{~km}$ away from Arba Minch town, $580 \mathrm{~km}$ away from Addis Ababa. The plant is further identified and authenticated by Prof. Sebsebe Demissew as Aloe gilbertii Sebsebe \& Brandham, subsp. gilbertii and Family - Aloaceae at the National Herbarium of Ethiopia (Voucher no 001), Department of Biology, College of natural science, Addis Ababa University. The collected plant sample was dried in a shaded area protected from direct sunlight and then grinded into powder using electrical grinder. Finally, the powder $(500 \mathrm{~g})$ of the sample was mixed with $500 \mathrm{~mL}$ of dichloromethane/methanol $(1: 1)$ and shaken by an electrical shaker at room temperature for 24 hours. And then, the extract was filtered. The residue was dissolved in $250 \mathrm{~mL}$ of the same solvent using the same procedure above. The filtrates were combined and evaporated by rotary evaporator to remove the solvent in the sample solution. This crude methanol: dichloromethane extract was $(0.5 \mathrm{~g}$ for each solvent) was partitioned with methanol, ethanol and ethyl acetate respectively. Each fraction was dried and weighed. The mass of each fraction was: $0.4 \mathrm{~g}, 0.38 \mathrm{~g}, 0.22 \mathrm{~g}$ of methanol, ethanol and ethyl acetate fraction, respectively. And then this fractions were suspended with $50 \mathrm{~mL}$ of distil water for further analysis.

\subsection{Preliminary Phytochemical Investigation}

The Phytochemical screening was conducted for the crude extract of $\mathrm{CH}_{2} \mathrm{Cl}_{2}: \mathrm{CH}_{3} \mathrm{OH}$ (1:1) of Aloe gilbertii Reynolds root. The presence of secondary metabolites were screened following standard procedures [21-25]

\subsubsection{Test for Alkaloids}

For identification of alkaloids, group and specific reactions are usually used. Most alkaloids are precipitated from neutral or slightly acidic solution. In this study, Solution of iodine in potassium iodide (Wagner reagent) was used as follwos: 0.2 gm of the crude extract was stirred with $2 \mathrm{~mL}$ of dilute hydrochloric acid and filtered. The filtrate was tested carefully with Wagner reagent.

Wagner's Test:-To $2 \mathrm{~mL}$ of filtrate, 5drops of Wagner's reagent was added by the side of the test tube. Wagner's reagent: Iodine $(1.27 \mathrm{~g})$ and potassium iodide $(2 \mathrm{~g})$ dissolved in $5 \mathrm{~mL}$ of water and made up to $100 \mathrm{~mL}$ with distilled water. A reddish brown precipitate confirms the presence of alkaloids. 


\subsubsection{Test for Saponins}

Foam Test-To $1 \mathrm{~mL}$ of the Extract was mixed with $5 \mathrm{~mL}$ of distilled water and shaken and observed for the formation of froth, which is stable for 10 minutes for a positive result.

\subsubsection{Test for Phenols}

Ferric Chloride Test- Extracts will be treated with 4 drops of ferric chloride solution. Formation of bluish black color indicates the presence of phenols.

\subsubsection{Test for Flavonoids}

\section{i. Alkaline Reagent Test}

The extract is mixed with few drops of sodium hydroxide solution. Formation of intense yellow color, which becomes colorless on addition of $2 \mathrm{ml} 10 \% \mathrm{HCl}$, indicates the presence of flavonoids.

\section{ii. Lead acetate Test}

Extract was treated with few drops of lead acetate solution. Formation of yellow color precipitate indicates the presence of flavonoids.

\subsubsection{Tests for Steroids}

Liebermann Burchard test:-The development of a greenish color when $2 \mathrm{~mL}$ of the organic extract was dissolve in $2 \mathrm{~mL}$ of chloroform and treated with sulphuric and acetic acids indicates the presence of steroids.

\subsubsection{Test for Anthraquinones}

Borntrager's test:-3mL of aqueous extract was mixed with 3 $\mathrm{ml}$ of benzene; filtered and $5 \mathrm{ml}$ of $10 \%$ ammonia solution was added to the filtrate. The mixture was shaken and the presence of a pink, red or violet color in the ammonical (lower) phase indicates the presence of free anthraquinone.

\subsubsection{Test for Phytosterols}

Libermann-Burchard's test:-The extract was treated with chloroform and filtered. The filtrate was again treated with few drops of acetic anhydride, boiled and cooled. Conc. Sulphuric acid was added. The formation of brown ring at the junction indicates the presence of phytosterols.

\section{Results and Discussion}

\subsection{Preliminary Phytochemical Analysis and Extraction Yield}

The results from the phytochemical screening test of the crude dichloromethane/methanol (1:1) extract using different chemicals reagents showed the presence of flavanoids, anthraquinone, Alkaloids, saponins, phenol and absence of steroids and phytosterols (table 1). This report agree with the previous report on root extracts of Aloe gilbertii [26].

Table 1. Phytochemical analysis of crude extract of $\mathrm{CH}_{2} \mathrm{Cl}_{2}: \mathrm{CH}_{3} \mathrm{OH}(1: 1)$ of aloe gilbertii Reynolds root.

\begin{tabular}{lll}
\hline Types of secondary metabolites & Chemical tests & Results of phytochemicals \\
\hline Test for alkaloids & Wagner's test & + \\
Test for saponins & Foam Test & + \\
Test for flavonoids & Alkaline Reagent Test & + \\
& Lead acetate Test & + \\
Test for steroids & Liebermann Burchard test - \\
Test for phenols & Ferric Chloride Test & + \\
Test for anthraquinones & Borntrager's test- & + \\
Test for phytosterols & Libermann-Burchard's test - \\
\hline
\end{tabular}

+: Presence; -: Absence.

Phytochemicals are currently receiving increased attention of the people due to their ability to act as a therapeutic agent, which make them as alternative medicine to treat different types of diseases [26] The anthraquinones, phenolics, flavonoids, saponins and alkaloids detected in these extracts could implicate these classes of phytochemicals as important bioactive agents of the root parts of this plant and might be involved in the therapeutic action. Medicinal plant is of a huge advantage to the health of individuals and community.
The crude dichloromethane/methanol (1:1) extract of roots of Aloe gilbertii Reynolds was partitioned in different solvents of varying polarity. The percent yields of the various fractions obtained are shown in Table 2. The highest yield was obtained in the methanolic fraction $(80 \%)$ while the lowest yield was in the ethyl acetate fraction (44\%). The percent yield obtained showed that the extract had a greater proportion of polar compounds as most of the extract was soluble in polar solvents.

\subsection{Percent Yield of the Various Extracts}

Table 2. Percent yield of the various extracts fraction of $\mathrm{CH}_{2} \mathrm{Cl}_{2}: \mathrm{CH}_{3} \mathrm{OH}(1: 1)$ of aloe gilbertii Reynolds root.

\begin{tabular}{llll}
\hline CE & Mass of each fraction Before drying in $\mathbf{g m}$ & Mass of each fraction After drying in gm & percent yield \\
\hline MF & 0.5 & 0.4 & $80 \%$ \\
EF & 0.5 & 0.38 & $76 \%$ \\
EtOACF & 0.5 & 0.22 & $44 \%$ \\
\hline
\end{tabular}


Where CE is crude extract and, ME, EF and EtOACF are methanol, ethanol, and ethylacetate fractions of Aloe gilbertii root extract.

\subsection{Results of Ferric Reducing Antioxidant Power (FRAP) Determination}

In this assay, the antioxidant capacity is measured on the basis of the ability to reduce ferric (III) ions to ferrous (II) ions. The FRAP assay is a simple method, and can be applied to both aqueous and alcohol extracts of plants. The reducing power assay is electron transfer reaction and is used to measure the reductive ability of antioxidant and it is evaluated by the transformation of $\mathrm{Fe}^{3+}$ to $\mathrm{Fe}^{2+}$ in the presence of the sample extracts. In the reducing power assay the reductants (antioxidants) in the test compounds reduce the $\mathrm{Fe}^{3+} /$ ferric cyanide complex, $\left[\mathrm{FeCl}_{3} /\left(\mathrm{K}_{3} \mathrm{Fe}(\mathrm{CN})_{6}\right]\right.$ to ferrous $\left(\mathrm{Fe}^{2+}\right)$ form. FRAP measures the ability of compounds to act as an electron donor. Therefore depending on the reducing power of the test compounds, the yellow color of the reagent solution changes to various shades of green or blue. The Prussian blue complex so formed can be measured spectrophotometrically at $700 \mathrm{~nm}$. The general chemical equation is shown in Scheme 1.

$$
\begin{gathered}
\mathrm{Fe}(\mathrm{CN})_{6}{ }^{3-}+\mathrm{ArOH} \rightarrow \mathrm{ArO}+\mathrm{H}+\mathrm{Fe}(\mathrm{CN})_{6}{ }^{4-} \\
\text { Yellow } \\
3 \mathrm{Fe}(\mathrm{CN})_{6}{ }^{4-}+4 \mathrm{Fe}^{3+} \rightarrow \begin{array}{c}
\mathrm{Fe}_{4}\left[\mathrm{Fe}(\mathrm{CN})_{6}\right]_{3} \\
\text { Prussian blue }
\end{array}
\end{gathered}
$$

Scheme 1. Reduction of $\mathrm{Fe}^{3+}$ to $\mathrm{Fe}^{2+}$ in the presence of antioxidants $(\mathrm{ArOH})$.

The reducing power (RP) of the extracts can be determined by direct electron donation in the reduction of ferric cyanide $[\mathrm{Fe}$ $\left.(\mathrm{CN})_{6}\right]^{3-}$ to ferrocyanide $\left[\mathrm{Fe}(\mathrm{CN})_{6}\right]^{4-}$. Addition of $\mathrm{Fe}^{3+}$ ions after the reduction reaction produced the intense Prussian blue color complex $\left(\mathrm{Fe}^{3+}\right)_{4}\left[\mathrm{Fe}^{2+}\left(\mathrm{CN}^{-}\right)_{6}\right]_{3}$ which absorbs at $700 \mathrm{~nm}$. In reducing power assay, antioxidants cause the reduction of the $\mathrm{Fe}^{3+}$ into $\mathrm{Fe}^{2+}$, thereby changing the solution into various shades from green to blue, depending on the reducing power of the compounds. Strong reducing agents, however, formed Perl's Prussian blue color [27] (table 3).

Table 3. Percent of reducing power in FRAP Assay.

\begin{tabular}{lllll}
\hline Concentration in $\mathbf{~ m} / \mathbf{m L}$ & $\mathbf{C E}$ & MF & EF & EtOACF \\
\hline 0.2 & $16.28 \pm 0.54^{\mathrm{a}}$ & $31.33 \pm 1.07^{\mathrm{b}}$ & $47.64 \pm 0.65^{\mathrm{c}}$ \\
0.4 & $30.68 \pm 0.96^{\mathrm{a}}$ & $42.07 \pm 0.0 .98^{\mathrm{b}}$ & $60.4 \pm 0.16^{\mathrm{C}}$ \\
0.6 & $32.45 \pm 0.63^{\mathrm{a}}$ & $59.73 \pm 0.47^{\mathrm{B}}$ & $61.14 \pm 0.07^{\mathrm{C}}$ & $28.69 \pm 0.26^{\mathrm{d}}$ \\
0.8 & $43.74 \pm 0.87^{\mathrm{a}}$ & $60.87 \pm 0.21^{\mathrm{B}}$ & $76.61 \pm 0.39^{\mathrm{C}}$ & $35.05 \pm 0.22^{\mathrm{d}}$ \\
1.0 & $56.58 \pm 0.42^{\mathrm{a}}$ & $65.31 \pm 0.28^{\mathrm{b}}$ & $77.49 \pm 0.06^{\mathrm{C}}$ & $56.64 \pm 0.17^{\mathrm{D}}$ \\
\hline
\end{tabular}

Small letters a-d in the column are mean difference significant at 0.05 , capital letters are insignificant.

It was observed that, the reducing power increased as the extract concentration increased.

Table 4. Antioxidant activities of the root of Aloe gilbertii crude and its fractions in reducing power assay.

\begin{tabular}{ll}
\hline Analysts of Aloe gilbertii & $\mathbf{A O A}^{\mathbf{a}}$ in terms of $\mathbf{~ m g ~} \mathbf{A A E}$ \\
\hline CE $/ 10$ & g dry weight \\
MF & $5.79 \pm 0.301$ \\
EF & $224.5 \pm 0.631$ \\
EtOACF & $241.5 \pm 0.112$ \\
\hline
\end{tabular}

The data are presented as mean \pm SD for triplicate analysis, where $\mathrm{AOA}^{\mathrm{a}}$ is antioxidant activity, $\mathrm{AAE}^{\mathrm{b}}$ is ascorbic acid equivalent, $\mathrm{CE}$ is crude extract and, $\mathrm{ME}, \mathrm{EF}$ and EtOACF are methanol, ethanol, and ethylacetate fractions of Aloe gilbertii root extract

The table showed, the ferric reducing potential the crude extract of showed less degree of $\mathrm{Fe}^{3+}$ reduction than the EtOAcF fraction and lees reducing power than methanol and ethanol fractions.

The ethanol fractions were generally more potent than the other fractions. Due to the active constituents in the plant are dissolved more readily in and where better extracted by ethanol.

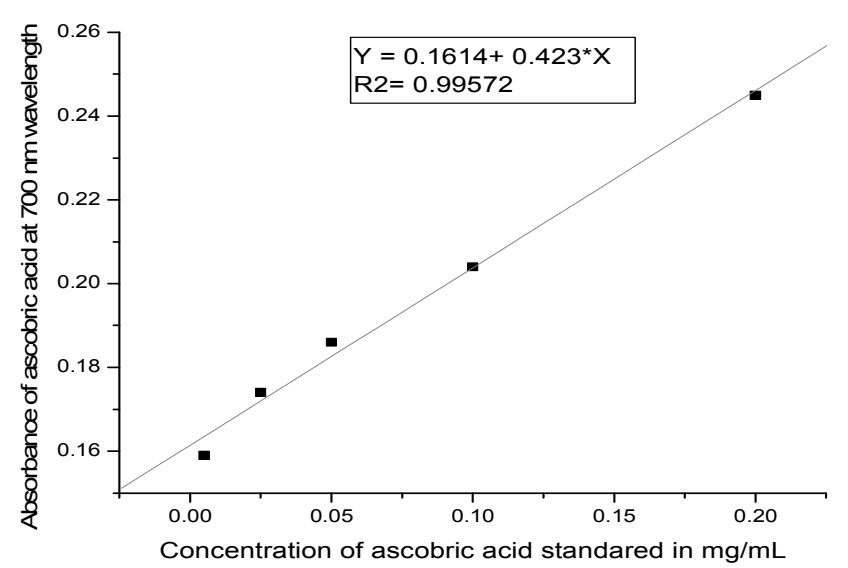

Figure 1. Calibration curve of a series of standard solution of ascorbic acid in reducing power. 


\subsection{Total Antioxidant Capacity Determination}

Total antioxidant capacity assay is a spectroscopic method for the quantitative determination of antioxidant capacity, through the formation of phosphomolybdenum complex. The assay is based on the reduction of Mo (VI) to Mo (V) by the sample analyses and subsequent formation of a green phosphate Mo (V) complex at acidic $\mathrm{pH}$. The absorbance of the aqueous solution is measured at $695 \mathrm{~nm}$ against blank in UV spectrophotometer [28-29] (table 5).

Table 5. Antioxidant activities of the crude root extract of Aloe gilbertii and its fractions in.

\begin{tabular}{ll}
\hline Analysts of Aloe gilbertii & $\mathbf{A O A}^{\mathbf{a}}$ in terms of $\mathbf{~ m g ~} \mathbf{A A E} \mathbf{b}^{\mathbf{b}} / \mathbf{1 0} \mathbf{g}$ dry weight \\
\hline $\mathrm{CE}$ & $64.90 \pm 0.043$ \\
$\mathrm{MF}$ & $82.21 \pm 0.028$ \\
$\mathrm{EF}$ & $88.75 \pm 0.016$ \\
EtOACF & $74.85 \pm 0.043$ \\
\hline
\end{tabular}

The data are presented as mean \pm SD for triplicate analysis, where $\mathrm{AOA}^{\mathrm{a}}$ is antioxidant activity, $\mathrm{AAE}^{\mathrm{b}}$ is ascorbic acid equivalent, $\mathrm{CE}$ is crude extract and, $\mathrm{ME}, \mathrm{EF}$ and EtOACF are methanol, ethanol, and ethyl acetate fractions of Aloe gilbertii root extract.

For the determination of total Antioxidant capacity, ascorbic acid is used as a reference standard from which plant extracts with potential antioxidant activity are evaluated and its calibration curve is drawn $=0.099+3.5 \mathrm{X}$ and linear regression coefficient $\left(\mathrm{R}^{2}=0.997\right)$.

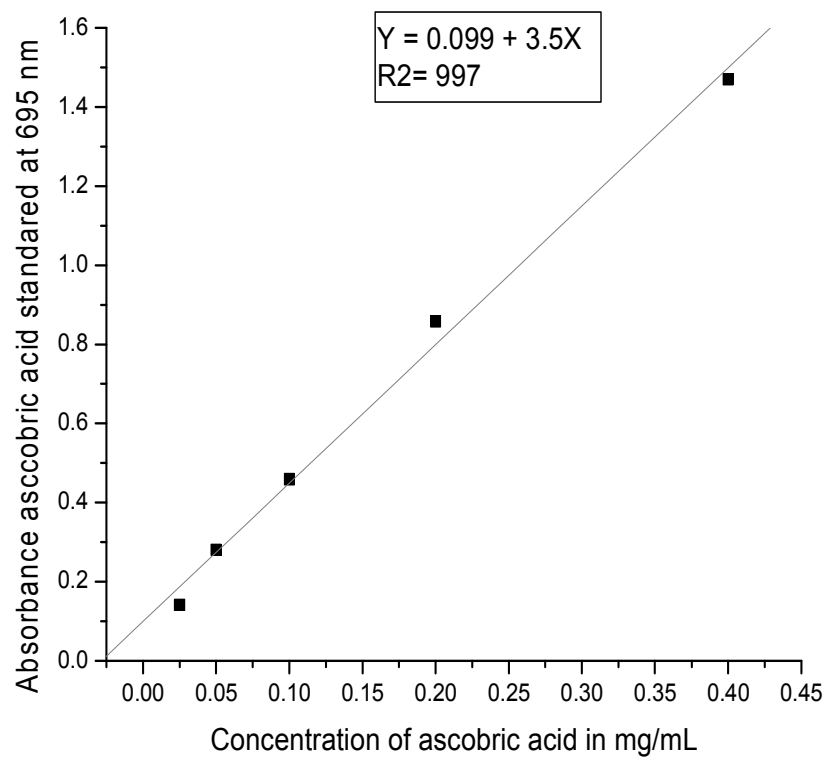

Figure 2. Calibration curve of a series of standard solution of ascorbic acid in Total antioxidant capacity assay.

The extracts showed different range of total antioxidant capacity and this may be associated with the high amounts of polyphenol compounds extracted in the corresponding solvent in plant extracts. The ethanolic fraction is highest total antioxidant capacity while the crude extract of showed the least total antioxidant capacity.

Thus this is an indication of different antioxidant capacity since the amount of phenolic compounds in the extracts may be different from one extract to the other.

\section{Conclusion}

In order to promote Ethiopian herbal drugs and traditional use of medicinal plants, there is an urgent need to evaluate the therapeutic potentials of the drugs as per the WHO guidelines. Bioactive extracts should be validated and standardized on the basis of phytochemical constituents.

Results of the phytochemical investigation on the roots of Aloe gilbertii revealed the presence of flavonoids, anthraquinone, Alkaloids, saponins, phenol and absence of steroids and phytosterols.

Previous phytochemical reports on the genus revealed that the genus has various medicinal uses and hence a couple of phytochemical screening and detail phytochemical analysis have been conducted on the various parts of the plant including the gel and roots. Nevertheless, to the best of our knowledge there were no prior phytochemical screening and phytochemical investigation done of the roots of Aloe gilbertii Reynolds. Thus, this works will be used as a reference material to initiate further research works on the roots of the plant so as to support the medicinal uses of the plant traditionally.

This study revealed that different solvent extracts of Aloe gilbertii root is able to reduce.

$\mathrm{Fe}\left[(\mathrm{CN})_{6}\right]^{3-}$ to $\mathrm{Fe}\left[(\mathrm{CN})_{6}\right]^{4-}$ and reduce $\mathrm{Mo}(\mathrm{VI})$ to $\mathrm{Mo}$ (V) in phosphomolbdate assay. This potential reflects that the electron releasing potential of the bioactive components in the extract fraction and it is related with its antioxidant activity. The reducing capacity of the test compound (extracts fraction) showed us, its antioxidant potential Aloe gilbertii.

\section{Acknowledgements}

The author is grateful to Arba Minch University, College of Natural Science, department of Chemistry for financial support and laboratory facilities.

\section{References}

[1] Stampfer, M. J. Primary prevention of coronary heart disease in women through diet and lifestyle. New Engl. J. Med. 2000, $343,16-22$.

[2] Hu, F. B. Diet, lifestyle, and the risk of type II diabetes mellitus in women. New Engl. J. Med. 2001, 345, 790-797.

[3] Jaiganesh, K. P., Arunachalam, G., Preliminary Phytochemical Screening And Antimicrobial Potential Of Pterospermum Canescens Roxb, (Sterculiaceae), International Journal of Pharmacy and Pharmaceutical Sciences, 2011, 3 (3), 140.

[4] S., Sharma; H. N., Verma. In-vitro antioxidant activity of seed extracts of Benincasa hispida. J. Nat. Prod. Plant Resour. 2013, 3 (4), 34-37, ISSN: 2231-3184.

[5] Key, T. J. The effect of diet on risk of cancer. Lancet. 2002, 360, 861-868. 
[6] S. N., Tyagi; R., Ajeet; A., Saxena; B. D., Patel. In-vitro Antioxidant Activity of Methanolic and Aqueous Extract of Flacourtia induce Merr. Am-Euras. J. Sci. Res. 2010, 5 (3), 201-206.

[7] Ramarathnam, N.; Osawa, T.; Namiki, M.; Kawakishi, S. Chemical studies on novel rice hull antioxidants. Isolation, fractionation, and partial characterization. J. Agric. Food Chem. 1988, 36, 732-737.

[8] Sebsebe Demissew and Nordal, I., (2010). Aloes and Lilies of Ethiopia and Eritrea. ColophonPage. Addis Ababa University andUniversity of Oslo. Pp. 42-109.

[9] Bhattacharjee, S., Paul, S., Dutta, S., and Chaudhuri, T. K. 2014. Antiinflammatory and protective properties of Aloe vera leaf crude gel in carrageenan induced acute inflammatory rat models. Int. J. Pharmacy and Pharmaceutical Sci., 6 (9): 368-371.

[10] Balemie K, Kelbessa E, Asfaw Z: Indigenous Medicinal Plant Utilization, Management and Threats in Fentalle Area, Eastern Shewa, Ethiopia. Ethiopian Journal of Biological Science. 2004, 3 (1): 37-58.

[11] Cunningham AB: African Medicinal Plants: Setting Priorities at the Interface between Conservation and Primary Healthcare People and Plants Working Paper 1. Paris; 1993.

[12] Hill AF: Economic Botany New Delhi: TATA McGRAWHILL PUBLISHING COMPANY LTD; 1989.

[13] Bolling, B.; Dolnikowski, G.; Blumberg, J.; Chen, C. Y. Food Chemistry., 2010, 122, 819-825.

[14] Md., Wasim; J. F., Ayala-Zavala; R. S., Dhua. Genotypic variation in tomatoes affecting processing and antioxidant attributes. Crit. Rev. Food Sci. Nutr. 2013.

[15] Ming-Chih, S.; Cheng-Ming, C.; Sue-Ming, K.; Min-Lang, T. Effect of Different Parts (Leaf, Stem and Stalk) and Seasons (summer and winter) on the Chemical Compositions and Antioxidant Activity of Moringa oleifera. Int. J. Mol. Sci. 2011, 12, 6077-6088.

[16] M., Naczk; R., Amarowicz; R., Zadernowski; Ronald B., Pegg; F., Shahidi. Antioxidant activity of crude phenolic extracts from wild blueberry leaves. Pol. J. Food Nutr. Sci. 2003, Vol. 12/53, SI 1, pp. 166-169.

[17] Sayed, A.; El-toumy, S. M.; Mohamed, E.; Abdel-Tawab, H. M. Phenolic Metabolites from Acacia nilotica Flowers and Evaluation of its Free Radical Scavenging Activity. Journal of American Science, 2011, 7 (3).
[18] Obasi NL, Egbuonu ACC, Ukoha PO, Ejikeme PM. Comparative phytochemical and antimicrobial screening of some solvent extracts of Samaneasamanpods. African journal of pure and applied chemistry 2010; 4 (9): 206-212.

[19] Dagne, E., Bisrat, D., Viljoen, A. \&VanWyk, B. E. 2000. Chemistry of Aloe species. Current Organic Chemistry. 4 (10): 1055-1078.

[20] Fikre Dessalegn (2013). study on the population of endemic aloe species (A. gilbertii Reynolds) in Ethiopia.

[21] Irshad, Md.; Zafaryab, Md.; Man Singh, M. Moshahid, A. Int. J. Med. chem., 2012, Article ID 157125, 6 pages.

[22] Ming-Chih, S.; Cheng-Ming, C.; Sue-Ming, K.; Min-Lang, T. Int. J. Mol. Sci., 2011, 12, 6077-6088.

[23] Sethi PD: HPTLC Quantitative Analysis of Pharmaceutical Formulations, $1^{\text {st }}$ ed. CBS Publishers and Distributors, NewDelhi. 1996; 3-73. Roopashree TS, Dang R, Rani SRH, Narendra C. Antibacterial activity of anti-psoriatic herbs: Cassia tora, Momordicacharantia and Calendula officinalis. International Journal of Applied Research in Natural Products. 2008; 1 (3): 20-28.

[24] Evans WC. Trease and Evans Pharmacognosy. General methods associated with the phytochemical investigation of herbal products. 2002; pp 139-143.

[25] Atawodi, S. E. Evaluation of the polyphenol content and Antioxidant properties of methanol extracts of the leaves, stem, and root barks of Moringa oleifera Lam. J. Med. Food. 2010, 13 (3), 710-716.

[26] Asmare, A. and Kesara, Na-B. Ch. Afr. J. Pharm. Pharmacol., 2015, 9 (25), pp. 615-627.

[27] Cho, E. J.; Yokozawa, T.; Rhyu, D. Y.; Kim, S. C.; Shibahara, N.; Park, J. C. Phytomedicine., 2003, 10, 544.

[28] Aberra, M.; Workinesh, T; Tegene, N. Effects of feeding Moringa stenopetala leaf meal on nutrient intake and growth performance of Rhode Island Red chicks under tropical climate Subtrop. Agroecosyst. 2013, 14, 485-492.

[29] Mekonnen, Y. The multi-purpose Moringa tree in Ethiopia. Examples of the development of pharmaceutical products from medicinal plants. UN development program, New York. 2011, 10, 111-117. 